\title{
REVITALISASI RADIO LOKAL KOTA METRO LAMPUNG SEBAGAI MEDIA PENDIDIKAN PERSPEKTIF INDUSTRI MEDIA
}

\author{
Kuliyatun \\ Fakultas Agama Islam \\ Universitas Muhammadiyah Metro \\ E-mail: kuliyatun.aulia@yahoo.co.id
}

\begin{abstract}
The function of mass mediacommunity has not run balanced.Especially with regard to social control and provide information regarding the importance of education to the general public.Local media in Metro Lampung has not been seriously considered as a comprehensive educational media. In fact, the mass media has a function to educate, entertain, inform, and as social control.The question in this article, how to revitalize the local SSB radio 92.1 FM in Kota Metro Lampung as educational media perspective Media Industry?. This paper uses the theory of Industry(Branston dan Stafford: 2018261).As the local media in Metro Lampung should be revitalized as a medium of education, through partnerships with LSM, foundations, private companies and others in order to obtain lucrative advertising.Local media industry has potential as a learning medium that is comprehensive and easily accepted by society. In educational institutions so that policies can be transferred effectively and efficiently in the community.
\end{abstract}

Keyword: Local Radio, EducationMedia, Media Industry

\section{PENDAHULUAN}

Kesadaran masyarakat terhadap pentingya pendidikan masih tergolong rendah. Padahal pendidikan merupakan pondasi penting dalam mewujudkan generasi masa depan yang berkualitas. Undang-undang dasar negara RI tahun 1945 disebutkan bahwa setiap warga negara berhak mendapatkan pendidikan. ${ }^{1}$ Pendidikan nasional berfungsi untuk mengembangkan kemampuan dan membentuk watak serta peradaban bangsa yang bermartabat dalam rangka mencerdaskan kehidupan bangsa. ${ }^{2}$

Pelaksanaan pendidikan oleh Cooms \& Manzoor tahun 1974 sebagaimana dikutip Nursehan Sugiharto diklasifikasikan kedalam pendidikan formal, informal dan non-formal. ${ }^{3}$ Pendidikan formal mulai tingkat dasar, menengah sampai perguruan tinggi baik strata satu, dua dan tiga. Pendidikan informal bisa didapatkan melalui pengalaman hidup sehari-hari termasuk

XIII.

${ }^{1}$ Undang-Undang Dasar Republik Indonesia tahun 1945 pasal 31 ayat 1 sampai ayat 5 pada bab

${ }^{2}$ Undang-Undang Nomor 20 tahun 2003 tentang Sistem Pendidikan Nasional bab II Pasal 3.

${ }^{3}$ Nursehan Sugiharto, kebijakan Pendidikan dan Implementasi di Kabupaten Purwanta (Tesis: UI, 2012), 36. Lihat juga Sudjana S., Pendidikan Non Formal Wawasan Sejarah Perkembangan Filsafat Teori Pendukung Azas, Bandung: Falah Production, 2004, h. 22. 
dilingkungan kehidupan keluarga, hubungan dengan tetangga, lingkungan kerja, pasar, dan media massa. Media massa menjadi bagian dari pendidikan informal mengingat pengaruhnya yang begitu besar terhadap khalayak/publik, karena itu, media massa semakin hari mendapatkan tempat dihati masyarakat. Kendatipun media massa sekaligus dijadiKan sebagai bisnis dengan keuntungan luar biasa. Industri media baik media cetak (koran, tabloid, majalah, buletin dan lainnya) maupun media elektronik (radio, televisi, film).

Di Indonesia, kehadiran media massa seperti Radio sudah dikenal sejak 11 September 1945 di Jakarta. Kemudian berkembang kedaerah lainnya seperti RRI Makassar sejak tahun $1967 .{ }^{4}$ Media tersebut dijadikan sebagai alat komunikasi pemerintah kepada masyarakat. Pada awalnya untuk menjaga keutuhan dalam mempertahankan kemerdekaan. Selanjutnya berfungsi sebagai hiburan, informasi dan pendidikan. ${ }^{5}$ Perkembangan dan keberadaan radio yang dikelola secara resmi oleh pemerintah, tidak menyurutkan keinginan pengusaha dalam mewujudkan radio swasta dan atau radio komunitas. Radio nonpemerintah yang ada di Metro Lampung misalnya banyak didirikan sejak era reformasi sampai saat ini terdapat sekitar 20-an radio yang masih eksis, antara lain, SSB 92,1 FM, Kartika 103.9 FM.

Meningkatnya industri media massa baik radio, televisi, media cetak dapat memberikan angin segar bagi masyarakat. Setidaknya, ada kesempatan bekerja dibidang industri media, kendatipun persaingannya sangat ketat. Selain perekonomian yang merasakan dampak dari media massa, juga bisa kaitkan dengan pengembangan sumber daya disektor pendidikan, politik, seni dan budaya dan lainnya. Karena, media satu dengan lainnya akan saling melengkapi dengan fungsi dasar yang sama, namun orientasi prioritas setiap media massa tentunya akan berbeda antara radio dengan televisi dan juga media cetak dengan pangsa pasarnya . Disinilah peneliti, ingin mengulas tentang perkembangan radio yang ada di metro lampung sebagai media pendidikan. Kendatipun bisnis melalui media radio. Pertanyaan dalam tulisan ini, bagaimana revitalisasi radio lokal SSB 92,1 FM di Kota Metro Lampung sebagai media pendidikan perspektif Industri Media? Pertanyaan tersebut akan dipertegas menjadi tiga permasalahan meliputi: 1) Siapa pengelola radio lokal di Metro Lampung yang memproduksi media sebagai proses pabrik? Seperti apa organiasasi dan struktur serta produk siaran radio lokal di kota metro lampung? Upaya apa saja yang dilakukan radio lokal Metro Lampung dalam mendistribusikan dan memasarkan produksinya ?

\footnotetext{
${ }^{4}$ Baharuddin Ali, Penyiaran Islam Di Rri Makassar; Studi Pengembangan Metode Dan Materi Dakwah Pada Titian Ilahi 2005-2009, Disertasi: UIN Jakarta, 2011, h. 1-2.

${ }^{5}$ Onong Uchjana Effendy, Ilmu, Teori Dan Filsafat Komunikasi, Bandung: Citra Aditya Bakti, 2003, Cet. III, h. 138.
} 


\section{KAJIAN TEORI \\ Teori Industri}

Teori Industri menjelaskan tentang beberapa topik antara lain; 1) Memproduksi media layaknya sebuah pabrik; pabrik membutuhkan pemilik modal (investor), ada produksi, ada objek atau pangsa pasar yang bisa dievaluasi dan diteliti kepuasaannya terhadap produk, termasuk didalamnya mengenai hadirnya iklan (sponsor) agar produksi tetap eksis dan berkembang. 2) Jenisjenis industri media yang dimaksud adalah film, televisi, radio, koran, majalah, rekaman musik. 3) Tahapan dalam memproduksi media (jalinan kerjasama, pra produksi, produksi, pascaproduksi, distribusi-pemasaran), organisasi dan produksi media, lokasi atau keberadaan media baik yang berlaku ditingkat lokal atau global. ${ }^{6}$

Branston dan staffort mengemukakan bahwa produksi/indutri media merupakan aktivitas komersial sebagaimana industri (pabrik). Dimana sebuah pabrik tentunya memiliki komponen penting seperti adanya investor (penanam modal), ada barang yang diproduksi, ada pendistribusian barang (produk), ada penelitian terhadap pengguna produk terhadap kepuasaan penggunanya, sekaligus adanya iklan (sponsor). Menurutnya, industri media, terutama sejak tahun 1990an banyak mengalami perkembangan, mulai dari (1) Perfilman, (2) Televisi, (3) Penyiaran (radio), (4) Percetakan Koran (harian, buletin mingguan-tabloid), (5) Majalah, (6) Rekaman musik. Keenam industri media tersebut disebutnya sebagai industri media tradisional. Seiring perkembangan informasi, kini industri media merambah pada industri media digital. Yaitu media elektronik seperti layanan internet, game, komputer dan lainnya.

Berkaitan dengan dunia perfilman ini, Branston menekankan perkembangan yang pesat. Melalui produktivitas industri media, film-film telah meraup keuntungan yang besar karena mendapatkan respon baik dari konsumen. Sebagaimana disebutkan Branston, film berkreatifitas dengan saluran satelit dan televisi kabel. Kendatipun industri media memiliki resiko yang cukup besar dalam pengelolaannya. Membutuhkan pertimbangan yang matang dalam berbagai aspek. Misalnya industri media berbasis cetak mempertimbangkan banyak hal meliputi; 1) 'bahan berita' tidak homogen; keterampilan dan budaya, estetika dan penilaian politik dalam penentuan sebuah peristiwa yang akan dipasarkan sebagai 'berita'. 2) Harga berita bervariasi; sebagian terbebas dari harga jual, sebagian bisa ditarif dengan harga mahal untuk mengaksesnya. 3) Produk berita tidak tetap artinya bisa menyesuaikan selera pembaca. 4) pembiayaan untuk staf/karyawan yang pada umumnya membutuhkan pendanaan yang lebih besar, ini terkait dengan pentingnya sebuah skill/keterampilan yang khusus dalam produksi. 5) produk

${ }^{6}$ Gill Branston and Roy Stafford, The Media Student's Book, Third Edition, (London and New York: Routledge, 2003, h. 218-261. 
berita tertentu memiliki batasan waktu yang sangat terbatas, bisa sehari atau setengah hari. 6) keuntungan dari penjualan produk hanya sebagian kecil dalam bisnis, sebagian besar pendapatan didapatkan dari periklanan. Karena itu, iklan menjadi amat penting dalam pengembangan produksi. Kendati koran memiliki usia pendek, menurut Branston, produk yang dicetak seperti koran (buletin, tabloid, majalah bulanan, jurnal dll) memiliki nilai lebih jagka panjang sebagai sebuah bahan arsip dan atau dokumentasi pustaka yang bisa difungsikan dimasa-masa mendatang, karena saat ini data tersebut bisa dieksploitasi secara komersil pada CD-Rom dan Online.

Demikian halnya dengan industri media lainnya selain cetak. Seperti radio, televisi, music rekaman dan produksi film. Masing-masing memiliki resiko tersendiri sekaligus pangsa pasar yang tetap. Beberapa perbedaan tersebut antara media cetak dengan radio dan televisi misalnya, menurut Branston, setidaknya memiliki lima hal antara lain; pertama; produksi berkelanjutan dan distribusi. Kedua; pembiayaan yang tetap tinggi. Ketiga; proporsi yang tinggi dari pendapatan iklan. Keempat; distribusi universal dalam area terbatas (nasional, regional dan atau lokal). Kelima; produk yang dihasilkan fokusnya terutama pada 'hiburan' atau informasi. Sedangkan rekaman dan produksi film juga memiliki lima kategori yaitu; 1) produksi bersifat sporadis, bukan distribusi harian, arus keluar-masuknya pendapatan bersifat fluktuatif. 2) setiap produksi memiliki pendapatan yang terpisah (biaya tetap dapat dihindari). 3) pemasukan didapatkan dari penyewaan, penjualan dan penempatan produk. 4) tidak ada batasan dalam distribusi global yang potensial. 5) keluaran diambil untuk menjadi hiburan dan seni.

Adapun proses produksi industri media menurut Branston setidaknya terdiri dari enam tahapan, yaitu: pertama; negosiasi kesepakatan. Kedua; praproduksi. Ketiga; produksi. Keempat; pasca-produksi. Kelima; pemasaran atau distrisibusi. Keenam; pertunjukan. Sebagai contoh, industri media internet, yang menurut Branston memiliki ancaman tersendiri bagi media lainnya. Internet bisa menjadi sarana untuk membuka akses pada produk musik baru untuk para produsen atau pelaku dan konsumen. Atau bisa merusak struktur industri saat ini dan mengancam mata pencaharian produsen atau pelaku yang dalam jangka panjang mungkin tidak dapat dilanjutkan.

Masalahnya adalah bagaimana mengembangkan pasar untuk musik digital yang menjamin pembayaran royalti untuk bakat kreatif (komposer atau pemain atau produser). Ada dua bagian untuk masalah ini. Pertama, file MP3 sering tersedia gratis dari pengguna lain. Software Napster bisa mencari di Internet, menemukan pemasok dari MP3 spesifik dan mengatur transfer kepada siapa pun on-line yang menginginkannya. Napster.com secara efektif 'dibeli' oleh sebuah konsorsium termasuk Bertelsmann utama, yang diakui daya tariknya, tapi bertekad untuk mendirikan sistem sendiri yang bisa mengenakan biaya. Universal membeli situs asli di MP3.com, dan dua situs 
komersial lainnya diumumkan oleh konsorsium dari jurusan lain. tindakan hukum sukses melawan bajak laut Napster, tetapi program lain yang sejenis. Para perompak sampai di sana pertama di Internet, dan industri ini sekarang berusaha untuk menciptakan bisnis yang sah. Pengguna tetap enggan untuk membayar untuk MP3 dan mereka terus mencari pilihan bebas. Jika jurusan ingin tinggal dalam bisnis mereka akhirnya harus menemukan skema yang bekerja dan di mana mereka dapat mengenakan biaya yang pelanggan akan membayar.

Bagian kedua dari masalah adalah bahwa sekarang to'rip sangat mudah 'trek musik yang CD, menyimpannya sebagai MP3 dan kemudian membakarnya ke CD baru. CD kosong biaya kurang dari, dan perangkat lunak seperti Tunes Apple sangat mudah digunakan. Atau, MP3 bisa diunduh untuk pemain portabel seperti iPod atau setara PC-nya. Sebagai kemajuan teknologi telepon selular, sudah memproduksi perangkat kecil 'combi' yang akan bertindak sebagai telepon, koneksi internet (WAP), saku MP3 player iklan komputer.

Hal ini jelas dari apa yang terjadi bahwa beberapa pelaku industri yang membuat keuntungan yang baik dari situasi saat ini (produsen CD kosong dan penulis CD misalnya). Tapi pertanyaannya tetap, mengapa menghabiskan 15 pada CD ketika kurang dari 1 dan beberapa menit bekerja, Anda dapat meminjam satu dari teman dan menyalinnya? Masalah yang dihadapi industri ini muncul sebelum dengan menyalin $\mathrm{CD}$ ke tape. Yang menghasilkan kampanye, 'Home rekaman membunuh music', yang disponsori oleh industri dan para musisi itu sendiri. Namun, industri badai itu - sebagian karena muncul bahwa 'rumah kemiringan' sebenarnya juga pembeli berat CD. pembajakan problemof sama dalam segala bentuknya menghadapi studio film Hollywood. Mereka telah mengambil berbagai langkah, termasuk sinyal coding pada kaset video yang berhenti mereka sedang disalin ke sebagian VCR modern, yang adalah pabrik diprogram untuk membaca kode. Usaha pertama untuk mencoba skema serupa di CD gagal karena kode juga mencegah pelanggan yang membeli $\mathrm{CD}$ dari (cukup sah) memainkan $\mathrm{CD}$ pada komputer mereka. Menggunakan CD drive komputer sebagai sumber musik penting untuk bagian penting dari pasar: ribuan CD kembali embrassed major label, yang menarik diri rilis.

Apakah perusahaan benar-benar perlu khawatir tentang dampak menyalin? Bahwa penelitian penonton Hollywood terbaru menunjukkan bahwa orang yang membeli atau menyewa sebagian video dan DVD benarbenar pergi ke bioskop lebih sering daripada mereka yang membeli lebih sedikit. Mungkinkah orang yang menyalin CD juga membeli lebih banyak dan pergi ke lebih konser? Dari sampel dari 834 wawancara dengan pengguna internet di AS pada tahun 2001, perusahaan riset internasional Ipsos-Reid menyimpulkan bahwa; 1) Hanya 8 persen dari pengguna yang pernah 
download musik telah membayar untuk itu. 2) 84 persen tidak siap membayar untuk download, bahkan jika tidak ada musik gratis yang tersedia; 3) 81 persen telah meningkat atau dipertahankan pembelian mereka dari $\mathrm{CD}$, meskipun men-download materi gratis. 4) 84 persen adalah pengguna internet dalam meneliti informasi tentang band, tur dan album.

\section{PEMBAHASAN}

Penelitian ini fokus pada media massa lokal yang ada di Metro Lampung. Terdapat banyak medi massa baik cetak elektronik radio dan televisi yang berdiri sejak masa reformasi. Beberapa radio swasta didirikan oleh pengusaha (pemilik modal) demi mengembangkan usahanya dengan memanfaatkan media massa. Radio yang ada di Lampung dalam kurun waktu 10 tahun terakhir berjumlah sekitar 42 buah stasion. Namun, khusus yang ada di kota Metro terdapat stasiun radio SSB 92.1 FM yang dipilih sebagai salah satu radio yang aktif. Sedangkan televisi yang berkembang di Lampung terdapat sekitar 8 buah stasiun.

Tabel televisi di Lampung

\begin{tabular}{|c|c|c|l|c|}
\hline NO & Stasiun TV & Frekuensi & \multicolumn{1}{|c|}{ Jaringan } & Kabupaten/Kota \\
\hline 1 & TVRI & 40 UHF & TVRI & Bandar Lampung \\
\hline 2 & Tegar TV & 42 UHF & $\begin{array}{c}\text { TV9 } \\
\text { Nusantara }\end{array}$ & Bandar Lampung \\
\hline 3 & Siger TV & 46 UHF & CTV Network & Bandar Lampung \\
\hline 4 & Radar TV & 48 UHF & Jawa Pos TV & Bandar Lampung \\
\hline 5 & iNews TV & 50 UHF & iNews TV & Bandar Lampung \\
\hline 6 & NET. Lampung & 51 UHF & NET & Bandar Lampung \\
\hline 7 & Suma TV & 54 UHF & - & Bandar Lampung \\
\hline
\end{tabular}

Sumber: Komisi Penyiaran Indonesia Daerah

Radio SSB merupakan kepanjangan dari Swara Seruni Bikarama. Radio ini merupakan salah satu radio di Kota Metro dengan nama Udara Radio SSB FM. Radio SSB beralamatkan di Jalan Way Umpu No. 87 Rawasari III Kota Metro Kode Pos 34112, dengan Frekwensi FM 92,1 MHz, Call Singn PM8FFZ. Radio SSB berslogan The Hits Radio Family Station dengan format siaran music Infotaiment, bersahabat dan kekeluargaan. Radio SSB mempunyai program unggulan yaitu Manajemen Qolbu Pagi, Musik Teman Aktivitas, Tembang Kenangan, From Me To You, dan Nuansa Malam. Persentase Jenis Musik terdiri dari $90 \%$ dan barat 10\%. Radio SSB telah menjadi anggota PRSSNI dengan Nomor anggota: PRSSNI:727 - XI/1997.

\footnotetext{
${ }^{7}$ SSB FM berada dibawah PT. Radio Swara Seruni Bikarama, Jl. Way Umpu No. 87 Rawasari III Kota Metro Kode Pos: 34112 Telephone: 0725-7000856, 0828-8070-0856 Fax: 0725-43010 E-mail: ssbfmmetro@yahoo.co.id, lihat http://ssb.kartikassb.com/page/about-us.
} 
Radio SSB di siarkan dari jam 06.00-23.00 WIB dengan converage area meliputi; untuk kota metro di seluruh wilayahnya. di Lampung Timur tersebar di Sukadana, Purbolinggo, Sekampung, Pekalongan, dan Batang Hari. Sedangkan di Lampung Tengah bisa terjangkau di Kota Gajah, Gunung Sugih, Bandar Jaya, Kali rejo, di Lampung Selatan masuk ke Natar sampai Branti. Di Lampung Utara pada sebagian wilayahnya. Di Tanggamus meliputi Talang Padang, Gisting, Kota Agung. Sedangkan di Pringsewu pada sebagian wilayah. Di Pesarawan sampai pada Gedung Tataan, Gading Rejo, Tegineneng. Begitu juga di Tulang Bawang dan Bandar Lampung hanya sebagian wilayahnya. Sedangkan format radio SSB adalah Radio Keluarga. Format Siaran adalah Musik Dan Infotaiment Format Siaran Kata berupaka Kekeluargaan dan Bersahabat. Format Musik adalah Pop Indonesia $90 \%$, Barat 10\%. Program Unggulan dilaksanakan Morning Show, From Me To You, Bincang-Bincang On SSB (BBO SSB).

Adapun teknis program acara radio SSB tahun 2016, Sebagaimana dalam tabel berikut:

\begin{tabular}{|c|l|c|l|}
\hline No & \multicolumn{1}{|c|}{ Judul program } & Hari dan waktu & \multicolumn{1}{|c|}{ Deskripsi } \\
\hline 1 & Ceramah agama & $05.00-06.00 \mathrm{wib}$ & $\begin{array}{l}\text { Mengudarakan tokoh agama } \\
\text { tentang materi dakwah }\end{array}$ \\
\hline 2 & $\begin{array}{l}\text { Good Moorning } \\
\text { Metro }\end{array}$ & $06.00-10.00 \mathrm{wib}$ & $\begin{array}{l}\text { Menginformasikan berita atau } \\
\text { kegiatan pagi }\end{array}$ \\
\hline 3 & Cakrawala Dunia & $10.00-12.00 \mathrm{wib}$ & $\begin{array}{l}\text { Mengudarakan } \\
\text { mancanegara }\end{array}$ \\
\hline 4 & SSB Menyapa & $12.00-14.00 \mathrm{wib}$ & $\begin{array}{l}\text { Hiburan interaktif dengan } \\
\text { request }\end{array}$ \\
\hline 6 & From Me To You & $14.00-16.00 \mathrm{wib}$ & $\begin{array}{l}\text { Pendengar diberi kesempatan } \\
\text { request lagu favorit }\end{array}$ \\
\hline 7 & Oase SSB & $16.00-17.00 \mathrm{wib}$ & $\begin{array}{l}\text { Tantangan dan peluaang } \\
\text { Perusahaan }\end{array}$ \\
\hline 8 & Not Voice & $17.00-1900 \mathrm{wib}$ & - \\
\hline 9 & BBO & $19.00-21.00 \mathrm{wib}$ & Bincang-bincang on SSB \\
\hline 10 & Nuasa Malam & $21.00-23.00 \mathrm{wib}$ & Kajian tentang keluarga dll \\
\hline
\end{tabular}

Sumber: Company Profile kartikassb.com

Sedangkan agenda mingguan hanya terhadap pada hari ahad dan kamis. Kamis pada pukul 20.00-21.00 wib program bernama 'Kajian Ma'rifatullah'. Kajian ini dimaksudkan untuk mengakomodir pendengar SSB yang haus tentang info mengeni spiritual. Sedangkan pada hari minggu, terdapat tiga program; pukul 12.00-14.00 adalah reage mania, pukul 16.0017.00 wib program 'creative', dan pukul 20.00-22.00 wib adalah indo Top 20. 
Penyiar radio SSB ada empat, yaitu; 1) Rifky Arief kelahiran Lampung 18 Januari 1992. 2) Dendi Dinata, kelahiran Lampung 16 Mei 1990, 3) Nanda Kris Saputro, kelahiran Metro 12 Desember 1993, dan 4) Kris Nanda, kelahiran Batang Hari Lampung Timur 23 September 1994.

Profile pendengar radio SSB dikategorikan kedalam beberapa aspek; jenis kelamin, umur, dan pekerjaan. Jenis kelamin pria (55\%) dan wanita (45 $\%$ ), berdasarkan umur 15-19 tahun sebanyak 15\%, 20-29 tahun 35\%, usia 30-39 sekitar $35 \%$ dan diatas 40 tahun sekitar $15 \%$. Adapun berdasarkan pekerjaannya, pendengar SSB yaitu; ibu rumah tangga sekitar $30 \%$, pegawai atau karyawan sekitar $20 \%$, pekerja/buruh/tani sebanyak $10 \%$, wirausaha/wiraswasta sebanyak $10 \%$, dan untuk pendengar pelajar/mahasiswa $30 \%$.

Sedangkan Tarif iklan meliputi; 1) Kategori loose spot; untuk durasi 30 detik seharga Rp. 50.000, durasi 60 detik seharga Rp. 100.000. 2) Kategori adlibs; untuk durasi 60 detik seharga Rp. 100.000. 3) Sponsor program; terdiri dari bloking time; dan Insert. Bloking Time untuk durasi 30 menit seharga Rp. 1.500.000, durasi 60 menit Rp. 2.000.000. sedangkan insert yang berdurasi 5 menit seharga Rp. $220.000{ }^{8}$

SSB melakukan kerjasama dengan BANK BNI dalam mengembangkan dan melakukan transaksi pendanaan dari sponsornya. Alamat BN'46 Cabang Kota Metro J1. AH. Nasution No. 18 Kota Metro, atas nama PT. Radio swaraSeruniBikarama No. Rek: 0075307208.

\section{Analisis}

Berkembangnya media di daerah lokal merupakan bagian dari kebebasan masyarakat moern. Masyarakat modern saat ini menjadi lebih antusias terhadap perkembangan media jenis apapun. Tetapi tidak meninggalkan media-media lama yang telah tersebar didaerahnya. Radio SSB yang didirikan oleh PT. Swara Seruni Bikarama ini menurut Branstron merupakan jawaban atas perkembangan pola pikir manusia modern yang menjadi media ibarat industri pabrik. Dimana pemiliknya notabene adalah investor dengan dana/modal banyak untuk mengembangkannya. ${ }^{9}$ Walaupun kehadiran radio merupakan bagian pemenuhan kebutuhan atau harapan-harapan dari perubahan iklim komunikasi mengenai peristiwa ditengah masyarakat itu sendiri. Apalagi memasuki abad informasi, terlihat betapa media memiliki kekuatan dominan dalam memengaruhi setiap dimensi kehidupan manusia. ${ }^{10}$

\footnotetext{
${ }^{8}$ http://ssb.kartikassb.com/page/about-us, diaksek tanggal 2 November 2016

${ }^{9}$ Ibid

${ }^{10}$ Andi Faisal Bakti dan Venny Eka Meidasari, Trendsetter Komuniasi di Era Digital: Tantangan dan Peluang Pendidikan Komunikasi dan Penyiaran Islam, Jurnal Komunikasi Islam, Vol. 02, No. 01, Juni 2012. Fakultas Dakwah IAIN Sunan Ampel Surabaya, h. 2.
} 
Komunikasi massa akan tetap eksis dan berkembang karena melibatkan publik secara luas. Media massa mampu mendominasi lingkungan informal dan berada dimana-mana. ${ }^{11}$

Namun, mendirikan media termasuk radio tidak semudah membalikkan telapak tangan. Sebagaimana disebutkan Branston, membutuhkan investor yang banyak, terlebih bila pemiliknya merupakan pengusaha yang kaya. Maka cukup membutuhkan keseriusan dan pengembangan jaringan dalam optimalisasi medianya. ${ }^{12}$ SSB yang dipimpin oleh Tig Eri Wibowo ini memiliki keunggulan dalam pengembangan medianya. Dia merupakan sosok penting dalam perusahaan radio tersebut. Struktur kepegurusan dari radi SSB ini sebagai sebuah perusahaan industri media memiliki organisasi yang baik. Sebagaimana terlihat pada tabel berikut: Struktur manajemen radio SSB.

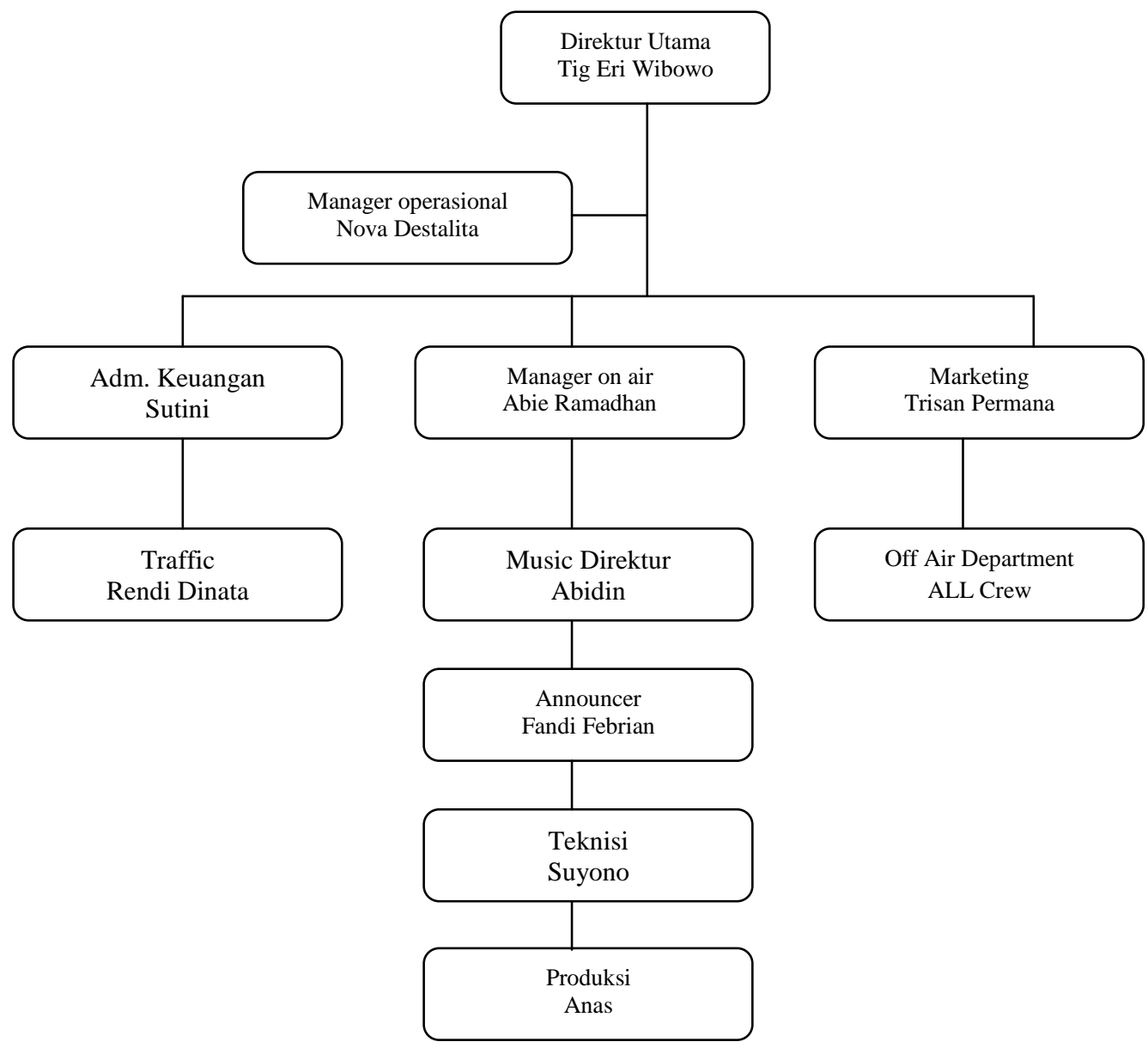

${ }^{11}$ Jalaluddin Rahmat, Psikologi Komunikasi (Bandung: Remaja Rosdakarya, 1986), h.191-193.

${ }^{12}$ Gill Branston and Roy Stafford, The Media Student's Book, p. 218-261. 
Pimpinan dalam radio SSB ini cukup serius dalam memproduksi siaran radionya. Ibarat produksi sebuah pabrik. Beberapa siaran yang diunggulkan oleh radio menjadi trendi tersendiri dikalangan pendengarnya. Seperti yang tampak pada program unggulannya ada Voice of Islam, From Me to You, BBO, Nuansa Malam, Tembang Kenangan. ${ }^{13}$ Demikian seperti yang disebutkan Branston, media harus memiliki produksi yang layak jual dan menarik hati konsumen, ${ }^{14}$ dalam hal ini, pendengar SSB. Acara unggulan seperti From Me to You, merupakan kajian petang yang memiliki serangkaian randown dengan durasi 2 jam dan konten yang beragam. Tepat jam 17.000 mengudarakan info PRSSNI yaitu siaran bersama berita lokal lampung. Sambil menunggu datangnya petang, waktu di mana masyarakat kota metro secara umum berpulang dari tempat aktivitas atau tempat kerjanya. ${ }^{15}$ Bahwa produksi media setidaknya terdiri dari enam tahap, yaitu: pertama; negosiasi kesepakatan. Kedua; pra-produksi. Ketiga; produksi. Keempat; pascaproduksi. Kelima; pemasaran atau distrisibusi. Keenam; pertunjukan. ${ }^{16}$

Pangsa pasar -dalam hal ini pendengar SSB- menurut Branstron merupakan sesuatu yang penting untuk dikembangkan. SSB merupakan radio format keluarga dengan musik dan infortaiment sebagai bagian dari penarik simpati pendengar. Apalagi pendengar dari kalangan pelajar atau mahasiswa lumayan banyak, yaitu sekitar $30 \%$, yang sama besarnya dengan pendengar dari kalangan ibu rumahtangga sebesar $30 \%$. Sedangkan pendengar dengan kategori umur paling tinggi ditempati antara usia 20-39 tahun. ${ }^{17}$ Mengingat pangsa pasar yang begitu besar peminatnya, bisa dipahami radio SSB ini merupakan media dengan potensi yang dapat menarik hati masyarakatnya dengan produk siaran yang baik dan memuaskan.

Bila dioptimalkan dengan baik, pangsa pasar ini diarahkan untuk mendengarkan info-info mengenai pentingnya pendidikan. Khususnya usia muda dengan pendidikan rendah yang masih relatife besar. Sebagaimana tercatat dengan tingkat sekolah dasar $5 \%$, sekolah menengah pertama $30 \%$, sedangakan menengah atas $50 \%$, dan yang paling kecil dengan strata satu (sarjana) haya $15 \%$. Pendengar dengan pendidikan rendah bisa dijadikan objek untuk mendengarkan tentang program kegiatan siaran pentinganya pendidikan dimasa mendatang. Sekaligus merupakan penyadaran bagi wali murid/siswa agar menyadari bahwa lembaga pendidikan masih memiliki harapan yang baik sebagai bagian dalam memenuhi kesejahteraan hidupnya. Dengan kata lain, pendidikan tinggi dengan ijazah resmi bisa disosialisasikan sebagai bagian hal yang penting bagi generasi muda. Karena mencerdaskan

${ }^{13}$ Wawancara dengan Nova Destalita, Penyiar dan manajer operasional. Wawancara, 04 Juni 2016.

\footnotetext{
${ }^{14}$ Gill Branston and Roy Stafford, The Media Student's Book, p. 218-261.

${ }^{15}$ Wawancara dengan Nova Destalita.

${ }^{16}$ Gill Branston and Roy Stafford, The Media Student's Book, p.218-261.

${ }^{17}$ Company Profile www.kartikassb.com, diakses tanggal 23 Oktober 2016
} 
kehidupan merupakan tugas pemerintah dan masyarakat luas dalam mewujdukan sumber daya manusia (SDM) yang berkualitas, produktivitas dan kecakaan mendayagunakan peluang yang ada. ${ }^{18}$

Untuk dapat menghasilkan kualitas SDM yang andal diperlukan adanya keseimbangan materi pendidikan, yang mengacu kepada pemberdayaan intelek, hati, dan psikomotorik, atau pendidikan yang memberikan bekal ilmu, akhlak dan keterampilan secara memadai dan seimbang. Upaya demikian dapat dilakukan melalui jalinan pendidikan formal, pandidikan dalam Lingkungan keluarga. ${ }^{19}$

Karena itulah media massa akan tetap mampu mencetak dan mengembangkan kualitas sumber daya manusia. Selain merupakan bagian dari kenyataan dimasyarakat, media massa merupakan inklude didalamnya sebagai media pendidikan. Baik media itu merupakan media lokal yang berkembang ditengah masyarakat terkecil sekalipun. Jaringan media memiliki komitmen menjadikan anggotanya sebagai pendukung utama komunikasi pembangunan di tingkat lokal (desa dan kecamatan) yang akan memberi efek domino pada keberhasilan pembangunan di tingkat yang lebih tinggi. Keberadaan jaringan media komunitas dapat memfasilitasi kebutuhan pengembangan kapasitas sumber daya untuk keberlanjutan dari keberadaan radio. ${ }^{20}$ Apalagi radio SSB ini merupakan salah satu radio swasta, bukan radio komunitas yang terbatas hanya pada jangkauan komunitas $2,5 \mathrm{KM} .{ }^{21}$

Salah satu program unggulan yang berkaitan dengan voice of islam dalam radio SSB ini bisa dikatagorisasikan sebagai radio dakwah juga, karena isinya menyangkut materi keislaman yang menjadi bagian dari dokrin agama yang dibutuhkan oleh masyarakat luas. Sebagai disebut ASM Romli, radio dakwah merupakan radio yang memiliki visi dan misi serta materi siaranya menyangkut syiar islam. ${ }^{22}$ Termasuk dalam acara mingguannya SSB menentukan acara kajian ma'rifatullah setiap hari kamis dengan durasi waktu 2 jam antara pukul 20.00-21.00 wib.

Radio SSB dalam mengembangkan dan mendapatkan sponsor dari iklannya selalu mengalami peningkatan dan relatif dinamis. Kendatipun nominal waktu yang disediakan dengan nominal yang bersaing dengan media lainnya. Karena iklan menjadi bagian yang penting pula dalam menjaga

${ }^{18}$ Anggan Suhandana, Pendidikan nasional Sebagai Instrumen Pengembangan Sumber Daya Manusia. Sumber daya manusia untuk Indonesia Masa Depan, Ed. Jimly Asshiddiqqhi, et. al., Jakarta: PT. Citra bangsa dan Mizan, 1997, h. 151.

${ }^{19}$ Yunasril Ali, Pendidikan yang Inovatif bagi Peningkatan Kualitas Sumber Daya Manusia, Innovation, Vol. VIII, No. 1, Januari-Juni, 2009. h.137.

${ }^{20}$ Nurul Purnamasari, dkk, Peran Jaringan Media Komunitas Dalam Mendorong Radio Komunitas Pada Pembangunan, dalam Pemakalah Konferensi CCCMS 2014, Membayangkan Indonesia baru, Yogyakarta: Program Studi Ilmu Komunikasi UII, 2014, h. 296-303

${ }^{21}$ Undang-Undang Republik Indonesia Nomor 32 tahun 2002 tentang Penyiaran.

22 ASM Romli, Antara Radio Dakwah dan Dakwah Radio, Hidayatullah.com, edisi September 2011. 
eksistensi media radio. Sebagaimana disebut Branston dalam semua jenis media apapun mulai film, televisi, koran, majalah dan rekaman musik termasuk radio pun membutuhkan kekuatan dan support dari peiklanan. ${ }^{23}$ Periklanan di radio SSB pun harus melakukan kerjasama dengan perusahaan lain atau organisasi yang mampu memberikan sumbagsih dalam iklannya. Sedangkan Tarif iklan meliputi; Kategori loose spot, Kategori adlibs, dan Sponsor program ${ }^{24}$

Media massa memiliki posisi stratesi dalam industri media. Sekalipun secara ekonomis dan politis, dominasi media massa mainstream memang sulit untuk dapat disandingkan dengan media komunitas. Tetapi untuk penegakan idealisme peran media massa dalam pembangunan, media komunitas mampu mendorong diri menjadi mitra strategis banyak pihak mengingat kedekatannya dan keterbukannya pada masyarakat. Kemampuan radio komunitas menangkap isu-isu aktual dalam bidang pembangunan tidak dapat dilepaskan dari keterlibatan masyarakat atau komunitasnya dalam memantik diskusi menjadi bahan olahan konten siaran. ${ }^{25}$

Keberadaan radio SSB ini berada dilokasi yang cukup strategis, disamping berada diwilayah perkotaan yang masyarakatnya antusias pada keberadaan media, radio juga aktif dalam memberikan empati kepada masyarakat sekitar. Beberapa program-program kegiatan yang dikembangkan dalam kurun waktu harian dan mingguannya menjalin hubungan yang interaktif antar pendengarnya dengan pengelola media melalui perantara penyiarnya. SSB memiliki wilayah cukup luas untuk kota metro di seluruh wilayahnya dan seterusnya.

Upaya untuk menarik pangsa pangsa pasar tersendiri dari kalangan terpelajar atau mahasiwa perlu ditingkatkan. Hemat penulis, radio SSB bisa juga melakukan inovasi dengan program kajian bahasa. Bahasa itu bisa mencakupbahasa internasional inggris dan atau bahasa arab sekalipun. Karena menurut penulis, bahasa arab juga menarik minat masyarakat khusus. Mengingat bahasa Arab merupakan salah satu bahasa resmi Internasional. ${ }^{26}$ Selain itu, Bahasa merupakan bagian dari struktur masyarakat. Sebagai

${ }^{23}$ Gill Branston and Roy Stafford, The Media Student's Book, 218-261.

${ }^{24} \mathrm{http}: / / \mathrm{ssb}$. kartikassb.com/page/about-us, diakses tanggal 23 Oktober 2016

25 Nurul Purnamasari, dkk, Peran Jaringan Media Komunitas Dalam Mendorong Radio Komunitas Pada Pembangunan, dalam Pemakalah Konferensi CCCMS 2014, Membayangkan Indonesia baaru, Yogyakarta: program Studi Ilmu Komunikasi UII, 2014, h. 296-303.

${ }^{26}$ C.H.M. Kees Versteegh, the language (edinburgh university press, 2014), second edition, 313. Latifa Al-Sulaiti and Eric Atwell, "The Design of a Corpus ofContemporary Arabic" International Journal of Corpus Linguistics 11:1 (2006), 2. A. Muradi, tujuan pembelajaran bahasa asing (Arab) di indonesia, jurnal al maqoyis, 2014, iain-antasari.ac.id 
struktur masyarakat bahasa mempunyai hubungan erat antara struktur sosial dan variasi bahasa. ${ }^{27}$

Kendatipun setiap pendenganr memiliki paradigma dan kecendurangan untuk memahami suatu objek secara berbeda antara diri sebagai individu dan sosialnya. Artinya, manusia memiliki aspek individual dan sekaligus social, dan seperti pengalaman individu lainnya, diri manusia dibentuk oleh teori pribadinya. Individu memahami dirinya dengan idea tau teori mengenai manusia (personhood) dan teori mengenal diri (selfhood) ${ }^{28}$. Mana kebutuhan diri yang segera harus dipenuhi dan mana kebutuhan masyaraka/sosial yang merupakan kebutuhan bersama. Hemat penulis juga, SSB juga perlu melakukan semacam survey dan atau kuesioner tentang ketertarikan pelajar atau mahasiswa terhadap program-program siaran baru yang terkait dengan kegiatan belajar mereka dilembaga pendidikan. Dengan demikian, akan sejalan dengan apa yang disampaikan Branston bahwa pangsa pasar dari industri media juga perlu dilakukan penelitian secara berkelanjutan, ${ }^{29}$ setidaknya bagi manajemen radio hasil dari penelitian itu bisa dijadikan evaluasi terhadap kinerja mereka selama ini. Dengan demikian, keberadaan pendengar bisa bertahan sekaligus kemungkinan akan bertambah banyak prosentase dari kalangan pelajar atau mahasiswa tersebut.

\section{SIMPULAN}

Radio SSB sebagai media massa lokal yang terus berkembang dan eksis di kota metro lampung sampai saat ini menjadi industri media yang masih relevan dengan kehidupan masyarakat kota. Pengelolaan dan manejemen radio SSB sejatinya sudah melakuka kerjasama yang baik dengan lembaga atau perusahaan lainnya. Kehadiran siaran radio yang disuguhkan kepada masyarakat, sebagai sebuah hasil produksi radio menunjukkan siaran yang masih kurang inovatif dan produktif. Respon dari pendengar radio terhadap program siaranan harus segera dilakukan oleh pihak manajemen guna mengetahui prosesntase ketertarikan masyarakat/audiennya.

Media lokal SSB di Metro lampung dimiliki oleh pengusaha dengan latar pendidikan rendah. Melalui kerjasama dan jaringan bisnisnya pengusaha mengembangkan media dengan produksi siaran yang baik serta didukung karyawan yang terdidik untuk memuasakan pendengarnya. Organisasi media radio lokal di Metro Lampung terintegrasi antara tokoh agama, pengusaha, politisi dan akademisi serta praktisi media. Upaya media massa lokal di metro lampung bekerjasama dengan LSM, yayasan, perusahaan swasta dan lainnya agar mendapatka iklan yang menguntungkan.

${ }^{27}$ Ismail Suardi Wekke, Model Pembelajaran Bahasa Arab (yogyakarta: deepublish, 201), 33-35. Nandang sarip hidayat, problematika bahasa arab, jurnal pemikiran islam, an-nida, vol 37, np. 1 januari-juni 2012, 82-88.

${ }^{28}$ Morissan dkk., Teori Komunikasi Massa, Bogor: Ghalia Indonesia, 2013, h. 134

${ }^{29}$ Gill Branston and Roy Stafford, The Media Student's Book, h. 218-261. 


\section{DAFTAR PUSTAKA}

Ali, Baharuddin. Penyiaran Islam Di Rri Makassar; Studi Pengembangan Metode Dan Materi Dakwah Pada Titian Ilahi 2005-2009. Disertasi: UIN Jakarta, 2011.

Ali, Yunasril, Pendidikan yang Inovatif bagi Peningkatan Kualitas Sumber Daya Manusia, Innovation, Vol. VIII, No. 1, Januari-Juni, 2009. 137.

Branston, Gill and Roy Stafford, The Media Student's Book, Third Edition, London and New York: Routledge, 2003.

Bakti, Andi Faisal dan Venny Eka Meidasari, Trendsetter Komuniasi di Era Digital: Tantangan dan Peluang Pendidikan Komunikasi dan Penyiaran Islam, Jurnal Komunikasi Islam, Vol. 02, No. 01, Juni 2012Morissan dkk., Teori Komunikasi Massa. Bogor: Ghalia Indonesia, 2013.

Muradi, A. Tujuan Pembelajaran Bahasa Asing (Arab) Di Indonesia, Jurnal Al Maqoyis, 2014, iain-antasari.ac.id

Purnamasari, Nurul., dkk. Peran Jaringan Media Komunitas Dalam Mendorong Radio Komunitas Pada Pembangunan, dalam Pemakalah Konferensi CCCMS 2014, Membayangkan Indonesia Baru. Yogyakarta: program Studi Ilmu Komunikasi UII, 2014.

Latifa Al-Sulaiti and Eric Atwell, The Design of a Corpus ofContemporary Arabic, International Journal of Corpus Linguistics 11:1. 2006.

Romli, ASM. Antara Radio Dakwah dan Dakwah Radio, Hidayatullah.com, edisi September 2011,.

Rahmat, Jalaluddin. Psikologi Komunikasi. Bandung: Remaja Rosdakarya, 1986.

Suardi Wekke, Ismail. Model Pembelajaran Bahasa Arab (Yogyakarta: deepublish, 201), 33-35. Nandang sarip hidayat, problematika bahasa Arab, jurnal pemikiran islam, an-nida, vol 37, np. 1 januari-juni 2012

Sugiharto, Nursehan. kebijakan Pendidikan dan Implementasi di Kabupaten Purwanta. Tesis: UI, 2012.

Sudjana S., Pendidikan Non Formal Wawasan Sejarah Perkembangan Filsafat 
Teori Pendukung Azas. Bandung: Falah Production, 2004.

Suhandana, Anggan. 'Pendidikan nasional Sebagai Instrumen Pengembangan Sumber Daya Manusia”. Sumber daya manusia untuk Indonesia Masa Depan, Ed. Jimly Asshiddiqqhi, et. al. Jakarta: PT. Citra bangsa dan Mizan, 1997.

Uchjana Effendy, Onong. Ilmu, Teori Dan Filsafat Komunikasi. Bandung: Citra Aditya Bakti, 2003.

Undang-Undang Dasar Republik Indonesia tahun 1945 pasal 31 ayat 1 sampai ayat 5 pada bab XIII.

Undang-Undang Nomor 20 tahun 2003 tentang Sistem Pendidikan Nasional bab II Pasal 3.

Undang-Undang Republik Indonesia Nomor 32 tahun 2002 tentang penyiaran.

Nova Destalita, Penyiar dan manajer operasional. Wawancara, 04 Juni 2016.

Versteegh, C.H.M. Kees. The Language , Edinburgh university press, 2014,, second edition.

http://ssb.kartikassb.com/page/about-us 